have been of the order of $10 \mathrm{sec}$. No phase could be found to correspond with an interval of $7 \cdot 5$ sec., as read by Dahm, and if it is assumed that the second phase is $\bar{F}$, then a focal depth somewhat greater than $10 \mathrm{~km}$. is indicated. This would tend to diminish the discrepancy between Dahm's determination of the focal depth, and that given in the Hawke's Bay earthquake report.

It should be mentioned that the re-examination of the Takaka seismogram did not appear to warrant any serious alterations to the original interpretation from which the focal depth of 10-15 miles (16-24 km.) was determined. Further, although Jeffreys' theory regarding the waves in near earthquakes has been somewhat modified in a more recent paper ${ }^{4}$, the apparent delay of the $P g$ wave would still lead to a determination of focal depth.

From the foregoing statements, it is considered that Dahm's interpretation of the Takaka seismogram is open to question, and that his criticism of the Hawke's Bay earthquake report is not justified.

Dominion Observatory, R. C. HAYES,

Wellington, N.Z. April 24.

${ }^{1}$ C. E. Adams, M. A. F. Barnett and R. C. Hayes, Seismological Report of the Hawke's Bay Earthquake of 1931, February 2-3. Dominion Observatory Bulletin 85 .

' H. Jeffireys, "The Earth". 2nd Edition.

' H. Jeffreys, "The Earth". 2nd Edition. lated from the Macelwane $\boldsymbol{P}$ curve, 1933", Bull. Seis. Soc. America, 28,1 (1936).

"H. Jeffreys, "A Rediscussion of Some Near Earthquakes", Geophys. Supp., Mon. Not. Roy. Ast. Soc., 3, No. 3, March 1933.

\section{Continuous Spectra of Certain Types of Stars and Nebulæ}

Mr. W. M. H. GReaves ${ }^{1}$ has made certain objections to my tentative explanation of secondary maxima in the continuous spectra of novæ, etc. ${ }^{2}$, because the observations of Nova Herculis 1934 made by various observers do not fully agree.

I should like to point out that a close inspection of the curves given by Beileke and Hachenberg ${ }^{3}$ discloses, however, the presence of a secondary maximum in most curves at practically the same wave-length as observed by Barbier, Chalonge and Vasy ${ }^{4}$ and reproduced in my note. The results of the unpublished Greenwich observations are, of course, unknown here.

However, leaving aside the Nova Herculis 1934 spectrum, we find, in the spectra of several former novæ, the presence of secondary maxima upon which I based my theory of two different types of continuous emission spectra in novæ, etc., superimposed on each other. Whether or not one of these emissions is continuous electron radiation is an open question. I only wish to direct attention to this type of emission, the existence of which does not seem to be generally realized. This type of spectra is quite different from the Planck black body radiation on which most astrophysical theories are based. I believe that the continuous electron emission will help in explaining several phenomena observed which have not been accounted for so far.

Berkeley, California.

WiLli M. Cohn. May 26.

1 W. M. H. Greaves, NATURE, 137, 405 (1936).

W. M. Cohn, NATURE, 187, 150 (1936).

F. Beileke and O. Hachen berg, Z. Astrophys., 10, 366 (1935).

- D. Barbier, D. Chalonge, E. Vasy, C.R., 201, 128 (1935).
The Teaching of Science in Schools

Av account of a conference on general science opened by the president of the Royal Society appeared in NATURE of April 11, p. 626. This association of prominent men of science with secondary education is very desirable. I write to suggest that the present is a very critical time for science teaching in schools, and that men of science may now be able to give help in a more effective way than by presiding at meetings and conferences.

Such help has been given in the past. In 1918 a committee of which Sir J. J. Thomson was chairman issued a report on the teaching of science and made many valuable suggestions. A few of these have been carried out, but only a few ; in the meantime, conditions have altered, and the whole question needs reconsideration. The recent conference represents a belated attempt to implement recommendation No. 17 of that report :

"That the science work for pupils under 16 should include, besides physics and chemistry, some study of plant and animal life."

To do this in the limited time at the teacher's disposal presents difficulties, but this recommendation must necessarily be read in conjunction with recommendation No. 8 :

"That in all secondary schools for boys the time given to science should not be less than 4 periods in the first year of the course from 12 to 16 , and not less than 6 periods in the three ensuing years."

This was published nearly twenty years ago, when the great necessity was to obtain for science some sort of recognition in our educational system. It would be expected that what was recommended then would be axiomatic now. Surprising as it may appear, the very body which was partly responsible for this recent conference expressed the intention of trying to formulate a generalized course in chemistry, physics and biology to occupy only 4 periods a week; that is, 3 hours or a little less.

If this proposal comes into being, we shall be back again in pre-scientific times. If I read the recommendation of the Thomson committee aright, it did not maintain that the 6 periods a week was an adequate time, but merely that it was as much as many schools under present conditions could be expected to give. A considerable number of schools have now approximately that time. There is a danger that the publicity which has been given to a particular sub-committee may lead to reduction of this inadequate minimum of time which many science teachers already have.

The whole problem of the school time-table is now in hopeless confusion. No attempt is being made, for example, to correlate the mathematics and the science in the manner suggested by the Thomson committee. Teachers of mathematics and science scrupulously respect each others' territory. The dominant influence is that of a group of headmasters who wish to keep the classical bias of the time-table, and this is probably the origin of the proposal to formulate a scheme for 4 periods a week, a proposal which was originally suggested by the Secondary Schools Examination Council. The time is ripe for another committee, similar to the old Thomson committee, to reconsider the whole question in the light of the conditions of the present day.

5 Ferry Road,

H. S. Shelton.

Teddington. 